\title{
A RESPONSABILIDADE DOS MECANISMOS DE BUSCA POR DANOS DECORRENTES DE CONTEÚDOS GERADOS POR TERCEIROS NA INTERNET
}

\author{
Camila Salgueiro da Purificação Marques* \\ Cinthia Obladen de Almendra Freitas**
}

SUMÁRIO: Introdução; 20 marco civil da internet e os seus princípios informadores; 3 Os mecanismos de busca na internet; 4 A responsabilidade dos mecanismos de busca no marco civil da internet; 5 Considerações finais; Referências.

RESUMO: O presente trabalho aborda a questão da responsabilidade dos mecanismos de busca na internet por danos decorrentes de conteúdos gerados por terceiros, especificamente em relação ao Marco Civil da Internet, o qual prevê a necessidade de ordem judicial para tornar indisponível o conteúdo ofensivo. Desse modo, equipara os mecanismos de busca aos provedores de aplicação ou serviço, incidindo a responsabilidade de retirar o conteúdo ofensivo, nos termos do artigo 19 e seguintes do marco civil da internet. Para tanto, sob o aspecto da Teoria do Diálogo das Fontes, consideram-se os dispositivos constitucionais, o marco civil da internet e o Código de Defesa do Consumidor, assim como se privilegia a multidisciplinariedade ao emprestar conceitos da informática. $\mathrm{O}$ artigo teve por base o método lógico-dedutivo, transportando conhecimentos da área tecnológica para compreender desde os mecanismos de busca até a responsabilidade por danos decorrentes de conteúdo gerado por terceiros.

PALAVRAS-CHAVE: Responsabilidade; Mecanismos de busca; Marco civil da internet; Conteúdo gerado por terceiro.

\section{ACCOUNTABILITY OF SEARCH ENGINES FOR DAMAGES DUE TO CONTENTS PRODUCED BY THIRD PARTIES ON THE INTERNET}

ABSTRACT: The accountability of internet search engines for damages caused by contents produced by third parties is analyzed. This is especially due to the Internet Civil Mark which requires a court warrant so that offensive contents would become unavailable. Search engines are equivalent to Internet servers with the responsibility

\footnotetext{
Docente na Facear - Faculdade Educacional Araucária; Doutoranda no Programa de Pós-Graduação em Direito (PPGD) da Pontifícia Universidade Católica do Paraná (PUCPR), Curitiba, Brasil.

E-mail: camila_purificacao@yahoo.com.br.

** Doutora em Informática Aplicada pela Pontifícia Universidade Católica do Paraná (PUCPR); Docente Titular da Escola de Dirieto da Pontifícia Universidade Católica do Paraná (PUCPR); Docente Permanente do Programa de Pós-Graduação (Mestrado/Doutorado) em Direito (PPGD) da PUCPR), Curitiba, Brasil.
} 
of removing offensive contents according to Art 19 of the Internet Civil Mark. Based on the Theory of Source Dialogue, constitutional terms, the Internet Civil Mark and Consumers' Code, multidisciplinarity is employed in Information. The logical-deductive method was employed by transporting data from the technology regime to understand search engines and the accountability for damages caused by contents produced by third parties.

KEY WORDS: Accountability; Search engines; Internet's civil mark; Contents produced by third parties.

\section{LA RESPONSABILIDAD DE LOS MECANISMOS DE BÚSQUEDA POR DAÑOS DERIVADOS DEL CONTENIDO GENERADO POR TERCEROS EN INTERNET}

RESUMEN: En este trabajo se aborda la cuestión de la responsabilidad de los motores de búsqueda en Internet, por daños derivados de los contenidos generados por terceros, específicamente en relación con Internet Civil Marco, proporcionando la necesidad de una orden judicial para hacer salir el contenido ofensivo. Por lo tanto, iguala los motores de búsqueda a los proveedores de aplicaciones o de servicios, centrándose la responsabilidad de eliminar el contenido ofensivo, de conformidad con el artículo 19 del Marco de Internet Civil. Por lo tanto, desde el aspecto de la teoría de las fuentes de Diálogo, que se considera las disposiciones constitucionales, el Marco de Internet Civil y el Código de Protección al Consumidor, ya que da prioridad a multidisciplinario para prestar los conceptos de computación.

PALABRAS CLAVE: Responsabilidad; Los motores de búsqueda; Marco internet Civil; Contenido generado por un tercero.

\section{INTRODUÇÃO}

A tecnologia desenvolvida em função da Segunda Guerra Mundial tem sido aprimorada constantemente até os dias de hoje, mormente, no que diz respeito às armas e aos produtos das mais variadas espécies ${ }^{03}$. E não é diferente na internet e no mundo digital, o que nos faz refletir acerca da sociedade atual, individualista e excludente ${ }^{04}$, assim como sobre as normas incidentes nesse âmbito.

\footnotetext{
${ }^{03}$ Verificar: CARSON, Rachel. Primavera Silenciosa. São Paulo: Pórtico, 1969; WILSON, Edward O. Diversidade da Vida. São Paulo: Companhia das Letras, 1994.

${ }^{04}$ Verificar:BECK, Ulrich. Sociedade de risco. São Paulo: Ed. 34, 2010. LIPOVETSKY, Gilles. A felicidade paradoxal: ensaios sobre a sociedade de hiperconsumo. São Paulo: Companhia das Letras, 2007.
} 
Também se verifica um grande poder dado ao homem hoje, por meio da tecnologia, que, na maioria das vezes, encontra-se muito longe de qualquer limite ético ou jurídico. Nesse contexto, vale lembrar Dupas ${ }^{05}$, no tocante ao "público", que é o Estado de hoje enfraquecido; e ao "privado" que corresponde ao indivíduo, que está fortalecido, em razão do individualismo extremo, levando à intolerância. Isto é, tem-se um individualismo exacerbado e uma aversão à esfera pública. E todos aqueles que não têm acesso à tecnologia e ao conhecimento, acabam por ser excluídos.

Segundo Jonas ${ }^{06}$, e como bem ressaltou Dupas ${ }^{07}$, o grande desafio na era do homem extremamente individualista é descobrir uma ética para a humanidade, focando-se o princípio da responsabilidade, para se evitar danos às presentes e futuras gerações. Assim, para Hans Jonas, a ética kantiana não basta porque é a ética do presente e das relações individuais, ou seja, antropocêntrica. Tem-se que incluir as gerações futuras e o planeta como um todo. Por isso, o autor trata da ética da responsabilidade, que se preocupe com o futuro e com a práxis coletiva. Nas suas palavras, um imperativo adequado a um novo agir humano, assim seria: "aja de modo que os efeitos de sua ação sejam compatíveis com a permanência de uma autêntica vida sobre a terra" $"$.

E é no contexto dessa sociedade individualista que se analisa a questão da responsabilidade por conteúdo disponibilizado pelos mecanismos de busca na rede mundial de computadores, assim como a responsabilidade do provedor de aplicação. O artigo trata especificamente da responsabilidade dos mecanismos de busca, por danos decorrentes de conteúdos gerados por terceiros na internet, em relação ao Marco Civil da Internet (lei $\mathrm{n}^{0} .12 .965$ de 2014), que prevê a necessidade de ordem judicial para tornar indisponível o conteúdo ofensivo.

No que diz respeito à metodologia utilizada, a técnica de pesquisa é a documentação indireta, fazendo uso das seguintes espécies: pesquisa bibliográfica, documental, legislativa e jurisprudencial. E o método de abordagem é o lógico-dedutivo, que parte de premissas genéricas com a finalidade de particularizar o conhecimento, sendo que a análise realizada neste trabalho considera o diálogo entre as diversas fontes do direito, assim como é multidisciplinar, pois transporta conhecimentos da área tecnológica, mais especificamente da informática, para compreender o objeto em estudo.

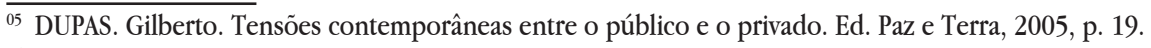

${ }^{06}$ JONAS, Hans. O princípio da responsabilidade. Ed. Contraponto, 2006.

${ }^{07}$ DUPAS, op. cit., p. 50.

${ }^{08}$ JONAS, Hans. O princípio da responsabilidade. Ed. Contraponto, 2006, p. 47.
} 
Deste modo, espera-se contribuir para discussões sobre o tema, permitindo futuras soluções que coadunem os mundos técnico e jurídico.

\section{O MARCO CIVIL DA INTERNET E OS SEUS PRINCÍPIOS INFORMADORES}

No marco civil da internet (lei $n^{\circ} .12 .965$ de 2014) são estabelecidos os princípios, as garantias, os direitos e os deveres para o uso da internet no Brasil, assim como se determina as diretrizes para atuação da União, dos Estados, do Distrito Federal e dos municípios em relação à matéria, nos termos do art. $1^{\circ}$. De modo que finalmente há uma regulamentação a respeito das relações jurídicas que foram transpostas para o mundo digital, tendo em vista a insuficiência dos tradicionais direito material e direito processual para tanto. ${ }^{09}$

Em relação aos princípios, destaca-se que alguns já se encontravam previstos na Constituição da República de 1988, como, por exemplo, a previsão de que é livre a manifestação do pensamento, sendo vedado o anonimato (art. $5^{\circ}, \mathrm{IV}$ ), assim como de que é livre a expressão da atividade intelectual, artística, científica e de comunicação, independentemente de censura ou licença (art. $5^{\circ}$, IX), e, ainda, de que a manifestação do pensamento, a criação, a expressão e a informação, sob qualquer forma, processo ou veículo não sofrerão quaisquer restrições (art. 220). Sendo que no marco civil da internet, há as correspondentes garantias de liberdade de expressão, comunicação e manifestação de pensamento (art. $3^{\circ}$, I). Além disso, a Constituição garante que são invioláveis a intimidade, a vida privada, a honra e a imagem das pessoas, assegurado o direito a indenização pelo dano material ou moral decorrente da sua violação (art. $5^{\circ}, \mathrm{X}$ ), assim como o marco civil faz menção à proteção da privacidade (art. $\left.3^{\circ}, \mathrm{II}\right)$.

Também é possível realizar um comparativo entre a Constituição da República de 1988 e o marco civil da internet, em relação aos objetivos. Isso porque, na Constituição, alguns dos objetivos da República são "constituir uma sociedade livre, justa e solidária; erradicar a pobreza e a marginalização e reduzir as desigualdades sociais e regionais; promover o bem de todos, sem preconceitos de origem, raça, sexo, cor, idade e quaisquer outras formas de discriminação", ao passo que o marco

${ }^{09}$ Inclusive, Sérgio Amadeu da Silveira defende que o Marco Civil visa garantir os direitos fundamentais dos cidadãos na rede, sendo resultado do combate às políticas que pretendiam que a internet tivesse sua dinâmica alterada por medidas de segurança exageradas. SILVEIRA, Sérgio Amadeu da. Marco Civil e a proteção da privacidade. Com ciência, n. 158, Campinas, maio de 2014. Disponível em: <http://comciencia.scielo.br/scielo. php?script $=$ sci_arttext\&pid=S1519-76542014000400008\&lng $=$ pt\&nrm =iso- $>$. Acesso em: 05 nov. 2016. 
civil prevê o acesso à internet para todos, ou seja, a inclusão digital (art. $\left.4^{\mathrm{o}}, \mathrm{I}\right)$. Assim como "é assegurado a todos o acesso à informação e resguardado o sigilo da fonte, quando necessário ao exercício profissional" (art. $5^{\circ}$, XIV, da CR/88), enquanto o marco civil prevê o acesso à informação, ao conhecimento e à participação na vida cultural e na condução dos assuntos públicos (art. 4º, II). A Constituição também tem por objetivo garantir o desenvolvimento nacional, enquanto o marco civil menciona a "inovação e fomento à ampla difusão de novas tecnologias e modelos de uso e acesso" (art. $\left.4^{\mathrm{o}}, \mathrm{III}\right)$. Por fim, constituem objetivos fundamentais garantir o desenvolvimento nacional (art. $3^{\circ}$, II, CR/88), assim como o Estado promoverá e incentivará o desenvolvimento científico, a pesquisa, a capacitação tecnológica e a inovação (art. $218^{\circ}$, caput, CR/88), sendo que o marco civil da internet trata da adesão a padrões tecnológicos abertos que permitam a comunicação, a acessibilidade e interoperabilidade entre aplicações e bases de dados (art. $\left.4^{\mathrm{o}}, \mathrm{IV}\right)$.

O Quadro 01 compara, a partir dos estudos de Schaal e Santos ${ }^{10}$, os demais princípios e fundamentos tanto da Constituição Federal quanto do marco civil da internet.

Quadro 01. Comparação entre princípios da Constituição Federal e do marco civil da internet

(Continua)

\begin{tabular}{|l|l|}
\hline \multicolumn{1}{|c|}{ Constituição Federal } & Dos princípios do marco civil \\
\hline $\begin{array}{l}\text { É inviolável o sigilo da correspondência e das } \\
\text { comunicações telegráficas, de dados e das co- } \\
\text { municaçóes telefônicas, salvo, no último caso, } \\
\text { por ordem judicial, nas hipóteses e na forma } \\
\text { que a lei estabelecer para fins de investigação } \\
\text { criminal ou instrução processual penal (art. } 5^{\circ},\end{array}$ & Proteção dos dados pessoais na forma da lei. \\
XII). & \\
\hline $\begin{array}{l}\text { Conceito técnico que garante que os pacotes } \\
\text { de dados que circulam na internet serão trata- } \\
\text { dos de forma isonômica, sem distinção por } \\
\text { conteúdo, origem, destino ou serviço em pro- } \\
\text { teção ao consumidor. }\end{array}$ & Preservação e garantia de neutralidade da rede. \\
\hline $\begin{array}{l}\text { Constituem objetivos fundamentais: garantir o } \\
\text { desenvolvimento nacional (art. } 3^{\circ}, \text { II); o Esta- } \\
\text { do promoverá e incentivará o desenvolvimento } \\
\text { científico, a pesquisa, a capacitação tecnológica } \\
\text { e a inovação (art. } 218, \text { caput). }\end{array}$ & $\begin{array}{l}\text { Preservação da estabilidade, segurança e fun- } \\
\text { cionalidade da rede, por meio de medidas } \\
\text { técnicas compatíveis com os padrões internac- } \\
\text { ionais e pelo estímulo do uso de boas práticas. }\end{array}$ \\
\hline
\end{tabular}

${ }_{10}$ SCHAAL, Flávia Mansur Murad; In: SANTOS, Natália Nogueira. Propriedade intelectual, Internet e o Marco Civil. São Paulo: EDIPRO, 2016, p. 46. 
(Conclusão)

\begin{tabular}{|c|c|}
\hline Constituição Federal & Dos princípios do marco civil \\
\hline $\begin{array}{l}\text { Conceito importante que divide a responsabili- } \\
\text { dade dos entes e agentes da internet de acordo } \\
\text { com as suas funções exercidas, esclarecendo a } \\
\text { responsabilidade subjetiva que outrora rechea- } \\
\text { va os tribunais em torno dessas discussões. }\end{array}$ & $\begin{array}{l}\text { Responsabilização dos agentes de acordo com } \\
\text { suas atividades, nos termos da lei. }\end{array}$ \\
\hline $\begin{array}{l}\text { É assegurado a todos o acesso à informação } \\
\text { e resguardado o sigilo da fonte, quando } \\
\text { necessário ao exercício profissional (art. } 5^{\circ} \text {, } \\
\text { XIV); é competência comum da União, dos } \\
\text { Estados, do Distrito Federal e dos municípios: } \\
\text { proporcionar os meios de acesso à cultura, à } \\
\text { educação, à ciência, à tecnologia, à pesquisa e à } \\
\text { inovação (art. } 23, \mathrm{~V}) \text {. }\end{array}$ & Preservação da natureza participativa da rede. \\
\hline $\begin{array}{l}\text { Liberdade de contratar e associar-se: é plena a } \\
\text { liberdade de associação para fins lícitos (art. } 5^{\circ} \text {, } \\
\text { XVII, } 1^{a} \text { parte). }\end{array}$ & $\begin{array}{l}\text { Liberdade dos modelos de negócios promovi- } \\
\text { dos na internet, desde que não conflitem com } \\
\text { os demais princípios estabelecidos na lei. }\end{array}$ \\
\hline
\end{tabular}

Fonte: adaptado de: SCHAAL (2016, p. 46).

Garcia $^{11}$ também anota que o marco civil da internet inaugura importante conjunto de fundamentos para a disciplina do uso da internet no Brasil: o respeito à liberdade de expressão; o reconhecimento da escala mundial da rede; os direitos humanos, o desenvolvimento da personalidade e o exercício da cidadania em meios digitais; a pluralidade e a diversidade; a abertura e a colaboração; a livre iniciativa, a livre concorrência e a defesa do consumidor; e a finalidade social da rede ${ }^{12}$.

Dessa forma, os princípios do uso da internet apontam para a proteção da privacidade, bem como para a proteção dos dados pessoais, "na forma da lei" (abrindo-se espaço para outras leis que podem dispor sobre o tema). E esse amplo e consistente conjunto de princípios é essencial para o uso e o desenvolvimento de uma rede livre, aberta, plural, não constituindo um rol taxativo, fechado ${ }^{13}$. Assim, segundo a mesma autora, o marco civil da internet ecoa "o decálogo de princípios para a governança e uso da internet no Brasil, firmados pelo Comitê Gestor da internet

\footnotetext{
${ }^{11}$ GARCIA, Rebeca. Marco Civil da Internet no Brasil: repercussões e perspectivas. Revista dos Tribunais, vol. 964, fev. 2016, p. 4.

${ }^{12}$ Continua a autora: Nota-se, aí, a preocupação do legislador em assegurar não apenas a internet como ambiente descentralizado, aberto e livre, mas em acentuar seu aspecto promocional - promoção de acesso e inclusão, de cidadania, de exercício de direitos, de desenvolvimento da personalidade. Isso sem perder de vista a inovação e a livre iniciativa e concorrência, de onde deriva a liberdade de desenhar, desenvolver e explorar modelos de negócio. Mantêm-se também os olhos na defesa do consumidor e na finalidade social da rede - afinal, os aspectos econômicos são importantes (inclusive para permitir a ampliação e desenvolvimento da infraestrutura que permite a interconexão da rede de redes), mas não devem ser um fim em si mesmo. Ibidem, p. 4-5.

${ }^{13}$ Ibidem, p. 5.
} 
no Brasil (CGI.br), entidade multissetorial crucial no desenvolvimento da internet no Brasil, para servir de base e de norte para ações e decisões na internet" ${ }^{14}$.

Portanto, a disciplina do uso da internet no Brasil tem como fundamento o respeito à liberdade de expressão, assim como o reconhecimento da escala mundial da rede, conforme o art. $2^{\circ}$, I da referida lei, ou seja, estas relações são marcadas pela "dispersão mundial". Além disso, também se fundamenta nos direitos humanos, no desenvolvimento da personalidade e no exercício da cidadania em meios digitais (inciso II), na pluralidade e na diversidade (inciso III), na abertura e na colaboração (inciso IV), na livre iniciativa, na livre concorrência e na defesa do consumidor (inciso VI); e na finalidade social da rede (inciso VI).

E a existência da rede por si só não alcançaria tamanho sucesso sem a possibilidade de interligação entre os usuários, principalmente por meio da transferência de conteúdos e dados entre os usuários, com a criação do protocolo de transferência conhecido como HTTP (Hypertext Transfer Protocol). E é pela possibilidade de conexão simultânea de milhares de pessoas que as relações jurídicas, decorrentes desta nova modalidade de comunicação, necessitam ser estudadas, regulamentadas e, em algumas situações, tuteladas.

Desse modo, o marco civil da internet traz conceitos elementares, como a definição de internet, terminal ou endereço IP (Internet Protocol) (art. $5^{\circ}$, I, II e III), assim como estabelece princípios e dá as diretrizes da regulamentação da Internet, que será objeto de interpretação e construção doutrinária e jurisprudencial. Além disso, há uma clara intenção em diferenciar os problemas relacionados à guarda, sigilo e responsabilidade sobre os dados dos usuários e o papel dos provedores. $\mathrm{E}$ dentre as maiores dificuldades verifica-se a tensão entre o direito à privacidade e o direito à informação, ou mesmo, entre o direito à privacidade e o direito ao esquecimento $^{15}$. "A proteção ao direito à intimidade e ao direito de não ser perturbado (the right to be alone) entra em colisão com o direito à informação sobre aquele que participa da rede virtual", sendo ambas as situações tuteladas pelo marco civil (art. $3^{\circ}$, I - direito à informação; II e III - proteção da privacidade e da intimidade) ${ }^{16}$.

\footnotetext{
14 Ibidem, p. 5.

15 PAZZINATTO, Carlos Henrique; FREITAS, Cinthia Obladen de Almendra. O Direito ao Esquecimento frente aos Mecanismos de Memória Eterna. Revista Opinião Jurídica (Fortaleza), v. 13, p. 82-107, 2015.

${ }^{16}$ ARAÚJO, Fabio Caldas. Reflexões sobre o Marco Civil da Internet. Consultor Jurídico. Disponível em: < http:// www.conjur.com.br/2014-jul-04/fabio-caldas-araujo-reflexoes-marco-civil-internet>. Acesso em: 05 nov. 2016.
} 


\section{OS MECANISMOS DE BUSCA NA INTERNET}

Diante dos princípios norteadores do marco civil da internet, assim como do objetivo do presente artigo no sentido de se verificar a responsabilização dos mecanismos de busca por conteúdos gerados por terceiros, há que se identificar o que são os mecanismos de busca na internet e como estes se enquadram na definição de provedores de aplicação.

Desse modo, primeiramente, destaca-se que, segundo Marcel Leonardi, os mecanismos de busca são programas de computador que executam diversas tarefas com o objetivo de possibilitar a localização de arquivos e web sites que contenham ou guardem relação com a informação solicitada pelo usuário ${ }^{17}$. Isto é, os denominados pesquisadores ou mecanismos de busca são sites especializados em localizar informações na internet. E realizam a procura a partir de um argumento de pesquisa com a finalidade de localizar e recuperar a indicação do local (página web) em que se encontra a ocorrência deste argumento (termo, palavra, frase ou expressão booleana) devidamente indexado em seus bancos de dados e apresentam os resultados na forma de uma lista de documentos da internet que contém o argumento de interesse ${ }^{18}$.

Mecanismos de busca são formados por software capaz de procurar, localizar e recuperar arquivos representados na internet. Para isto, a World Wide Web (WWW) conta como uma topologia estruturada por um protocolo de comunicação HTTP e pelos programas gráficos voltados a navegação nas páginas Web (Explorer, Google Chrome, Mozilla, entre outros). Tem-se, portanto, viabilizada a hipermídia (som, imagem, hipertexto).

Para Gabriel, ${ }^{19}$ os mecanismos de busca são sistemas de recuperação de informações com a finalidade de "auxiliar na busca de informações armazenadas em ambientes computacionais", sendo possível mensurar a utilidade por meio da relevância, ou qualidade do resultado, e velocidade de obtenção dos resultados.

Ou seja, é software capaz de varrer a rede mediante as requisições feitas pelos usuários, possuindo quatro principais funções: rastrear, indexar, ranquear e apresentar resultado. Destacando-se que não existe um contrato pré-estabelecido

${ }^{17}$ LEONARDI, Marcel. Responsabilidade Civil dos Provedores de Serviços de Internet. São Paulo: Juarez de Oliveira, 2005, p. 12.

18 BRANSKI, Regina Meyer. Localização de informações na internet: características e formas de funcionamento dos mecanismos de busca. Transinformação, Campinas, v. 12, n. 1, p. 11-19, June 2000. Disponível em: $<$ http://www.scielo.br/scielo.php?script $=$ sci_arttext\&pid $=$ S0103-37862000000100002\&lng $=$ en\&nrm $=$ iso >. Acesso em: 05 nov. 2016, p. 11.

${ }^{19}$ GABRIEL, Martha Carrer Cruz. Sem e Seo: dominando o marketing de busca. São Paulo: Novatec Editora, 2012, p. 36. 
entre os motores de busca e os produtores de conteúdo, pois numa frequência "alucinante" existem robôs de busca diariamente catalogando conteúdos e indexando páginas, podendo seus proprietários serem alheios a este processo ${ }^{20}$.

Além disso, os pesquisadores podem ser enquadrados em duas amplas categorias: catálogos por assunto e índices, tendo como principal diferença a forma como seus bancos de dados são compilados. É como destaca Branskii ${ }^{21}$, no sentido de que, diferentemente dos humanos, os mecanismos de busca são incapazes de formular perguntas adicionais que definam melhor o objeto ou de se valer de suas experiências anteriores para escolher, entre os arquivos ou documentos encontrados, os mais relevantes. De modo que, para uma maior eficiência, "utilizam critérios que envolvem localização e frequência da expressão procurada".

Ademais, verificam a existência dos termos buscados tanto no título, como nas primeiras linhas e o número de ocorrências, e, a partir desse levantamento, definem a localização de cada documento na relação apresentada como resposta à busca. No entanto, os resultados apresentados numa busca podem diferir de uma ferramenta para a outra, em razão dos métodos de indexação e das formas de funcionamento de cada ferramenta ${ }^{22}$ : a) a relação de páginas iniciadas a partir do qual o "spider" percorrerá a rede em busca de informação; b) as informações enviadas pelos próprios autores quando solicitam a inclusão; c) o modo como se indexam as

${ }^{20}$ MARINO, Aline Marques; PASSOS, Jonatas Fonseca. Dilemas do meio ambiente digital: o Marco Civil da Internet, a responsabilidade civil dos buscadores e os sites não indexados. In: Anais do II Congresso Internacional de Direito - CONIDIR, setembro de 2014, UBM, Barra Mansa, p. 9.

${ }^{21}$ BRANSKI, op. cit., p. 11-12.

${ }^{22}$ Sobre o assunto e a assimetria de poder em relação aos mecanismos de busca, João Costa Ribeiro Neto assevera que: "Os critérios com base nos quais são selecionados os resultados de uma determinada busca no Google deveriam ser mais transparentes do que são. A omissão de um nome ou um termo pode ser tendenciosa ou arbitrária. Não se sabe, ao certo, se tais dados são manipulados e, tampouco, há instrumentos de controle impostos pela lei, capazes de traçar exigências de transparência e equidade. Os riscos de abuso de poder (Risiken des Machtsmissbrauchs) são uma realidade, especialmente em virtude das elevadas assimetrias de poder (erhebliche Machtasymmetrien) 13 das partes envolvidas. De um lado, os usuários dos serviços Google e, do outro, o poderoso grupo econômico, que delibera sem ter que consultar o público antes de tomar suas decisões. Não há qualquer tipo de submissão dessas decisões à esfera pública ou crivo apto a filtrar alguns dos interesses privados que motivam tais decisões. O favorecimento a algum tipo de ideologia ou a algum grupo político nos resultados das buscas ou no compartilhamento de vídeos (no caso do YouTube) é capaz de implementar ou de extinguir tendências. Teoricamente, o cenário pode soar surreal, mas imagine-se, por exemplo, se a indicação de um local deixa de constar no Google Maps. Cada vez mais pessoas usam esse recurso para procurar indicações de atrações a visitar, de locais para alimentar-se etc. Não se pode menosprezar o quanto a vida de hoje é perpassada pela presença de entidades privadas. Se essa presença é menos sentida, embora já expressiva, ao que tudo indica, ela será cada vez maior, gerando a necessidade de se traçar, desde logo, os limites de atuação de uma instituição como o Google. É de se lembrar, por exemplo, que certos links do sistema de busca do Google são patrocinados. Esses "links patrocinados" são formas de publicidade e, no resultado de buscas, aparecem sempre antes dos demais. Há, inclusive, uma parte do Google responsável por administrar esse tipo de propaganda; trata-se do AdWords." RIBEIRO NETO, João Costa. A eficácia dos direitos fundamentais nas relações privadas: o caso Google. Revista de Direito Constitucional e Internacional, v. 83, p. 177-210, abr./jun, 2013. 
informações de cada site (texto integral ou pequeno resumo algoritmicamente construído do conteúdo, por exemplo); d) no caso dos catálogos, os critérios humanos utilizados para a indexação e classificação das informações ${ }^{23}$.

Assim, consoante adiante também se verificará com maior vagar, tendo em vista a exposição de conteúdo, ainda que por meio de busca em outros sites, os mecanismos de busca na Internet podem ser equiparados aos provedores de aplicação para fins de responsabilização por conteúdo gerado por terceiro, devendo se submeter à ordem judicial de retirada do conteúdo, nos exatos termos do art. 19 do marco civil da internet.

\section{A RESPONSABILIDADE DOS MECANISMOS DE BUSCA NO MARCO CIVIL DA INTERNET}

Inicialmente apresenta-se uma análise do marco civil da internet sob a ótica dos provedores de aplicação, visto que tal norma categoriza os provedores de internet em dois tipos, a saber: de conexão e de aplicação. Tecnicamente, tem-se uma categorização diferenciada, a qual inclui seis espécies de provedores: backbone, acesso, correio eletrônico, hospedagem, conteúdo e informação ${ }^{24}$. Os provedores de backbone e de acesso são os denominados provedores de conexão, sendo os demais provedores de aplicação. Tais categorizações são importantes à análise realizada neste artigo.

\subsection{ANÁLISE DO MARCO CIVIL DA INTERNET}

No tocante à responsabilidade dos provedores de aplicação na internet, o art. 19 do marco civil dispõe que com o intuito de assegurar a liberdade de expressão e impedir a censura, "o provedor de aplicações de Internet somente poderá ser responsabilizado civilmente por danos decorrentes de conteúdo gerado por terceiros se, após ordem judicial específica, não tomar as providências para, no âmbito e nos limites técnicos do seu serviço e dentro do prazo assinalado, tornar indisponível

\footnotetext{
${ }^{23}$ BRANSKI, op. cit., p. 13.

${ }^{24}$ ARAÚJO, Laíss Targino Casullo de; REIS, Sérgio Cabral dos. Responsabilidade civil dos provedores de conteúdo de internet. Âmbito Jurídico, Rio Grande, XIV, n. 93, out 2011. Disponível em: < http://www.ambito-juridico.com.br/site/?n_link=revista_artigos_leitura\&artigo_id $=10422>$. Acesso em: 05. nov. 2016. LEONARDI, op. cit.
} 
o conteúdo apontado como infringente", ressalvadas as disposições em sentido contrário constantes na legislação. Já o $\S 1^{\circ}$ prescreve que a ordem judicial de que trata o dispositivo deverá conter, sob pena de nulidade, identificação clara e específica do conteúdo apontado como infringente, permitindo "a localização inequívoca do material".

Apesar da regulamentação da questão, verifica-se que a jurisprudência deverá definir em quais situações esta responsabilidade será subsidiária especialmente pela falha do serviço quanto a não identificação do terceiro ofensor. "Para esta correta identificação os provedores de conexão, de aplicação ou mesmo aqueles responsáveis unicamente pela guarda e sigilo das informações necessitam preservar, com o devido sigilo os dados de conexão e dados de acesso aos aplicativos". Qualquer usurpação indevida constitui ilícito autônomo com previsão das sanções que vão de advertência (art. 12, I) até a proibição de exercer a atividade (art. 12, IV) ${ }^{25}$.

A doutrina também trata do disposto no art. 19 como "princípio da inimputabilidade na rede". E, "ao contrário do que o nome sugere, não significa que a rede seja terreno de irresponsabilidade, mas, sim, que os provedores a rigor não respondem civilmente pelos danos causados por conteúdo de terceiros, sobre o qual não têm ingerência"26.

Ademais, tendo em vista o devido diálogo das fontes, em caso de descumprimento da ordem judicial, defende-se que o provedor de aplicação pode ser responsabilizado solidariamente com o coautor do ato ofensivo, nos termos do art. $7^{\circ}$, parágrafo único do Código de Defesa do Consumidor e do art. 942 do Código Civil ${ }^{27}$. E esta exigência de ordem judicial específica também gerou acalorados debates, pois, até então, a jurisprudência vira construindo e consolidando o entendimento de que os provedores poderiam ser responsabilizados se não adotassem providências depois de notificados sobre o conteúdo objeto de discussão - isto é, vinha-se aplicando, de forma já substancialmente tranquila pelos tribunais, a regra do notice and takedown. No entanto, o marco civil da internet, acabou optando pela necessidade de ordem judicial específica, como uma garantia, tal qual tratado por Garcia28:

\footnotetext{
${ }^{25}$ ARAÚJO, Fábio Caldas, op. cit.

${ }^{26}$ GARCIA, Rebeca. Marco Civil da Internet no Brasil: repercussões e perspectivas. Revista dos Tribunais, vol. 964, fev. 2016, p. 7.

${ }^{27}$ OLIVEIRA, Carlos Eduardo Elias. Aspectos principais da Lei n. 12.965 de 2014, o Marco Civil da Internet: subsídios à comunidade jurídica. Brasília: Núcleo de Estudos e Pesquisas/CONLEG/Senado, abr./2014 (Texto para discussão n. 148). Disponível em: < www.senado.leg.br/estudos. Acesso em 29.04.2014 > . Acesso em: 05 nov. 2016, p. 20.

${ }^{28}$ GARCIA, op. cit., p. 7-8.
} 
Talvez se tenha pensado mais na rede em geral do que especificamente nas pessoas relacionadas a um conteúdo disputado. Sob essa perspectiva, simples notificações poderiam dar mais espaço a abusos pelos notificantes (em princípio livres para denunciar sem fundamentos qualquer conteúdo), a monitoramento preventivo ou a remoções imediatas e irrefletidas. Afinal, é razoável supor que seria mais simples e seguro remover automaticamente um conteúdo denunciado - a despeito de sua análise -, e assim evitar responsabilização, do que discutir o mérito da notificação e entrar no terreno por vezes difícil do juízo de valor sobre o conteúdo que se produz e publica no meio digital.

Privilegiou-se, assim, a liberdade de expressão, buscando-se evitar a censura prévia e o monitoramento online. Mas não são poucas - nem são infundadas - as críticas feitas a essa opção legislativa. O principal argumento é o de que essa opção restringe, ferindo-o, o princípio da ampla reparação dos danos, além da provável delonga que a concessão de uma ordem judicial específica implicaria - o ponto de vista parece concentrar-se, pois, na vítima.

No $\S 3^{\circ}$, prescreve-se que as causas que versem sobre ressarcimento por danos decorrentes de conteúdos disponibilizados na internet relacionados à honra, à reputação ou a direitos de personalidade, bem como sobre a indisponibilização desses conteúdos por provedores de aplicações de internet, poderão ser ajuizadas perante os juizados especiais, de modo a privilegiar a simplicidade e o acesso à justiça que estes proporcionam (o não pagamento de custas, maior celeridade na tramitação dos processos, etc.). E o $\S 4^{0}$ dispõe que o juiz, inclusive no procedimento previsto no $\S 3^{\circ}$, poderá antecipar, total ou parcialmente, os efeitos da tutela pretendida no pedido inicial, existindo prova inequívoca do fato e considerado o interesse da coletividade na disponibilização do conteúdo na internet, "desde que presentes os requisitos de verossimilhança da alegação do autor e de fundado receio de dano irreparável ou de difícil reparação".

Nesse contexto, destaca-se que, de acordo com o novo Código de Processo Civil, lei $\mathrm{n}^{0} .13 .105$ de 2015, em vigor desde março de 2016, a tutela provisória constitui-se em "conjunto de técnicas que permite ao magistrado, na presença de determinados pressupostos, que gravitam em torno da presença da "urgência" ou da "evidência", prestar tutela jurisdicional, antecedente ou incidentalmente, com base em decisão instável (por isto, provisória) apta a assegurar e/ou satisfazer, desde logo, a pretensão do autor". (BUENO, 2016, p. 247). Inclusive, no novo Código de Processo Civil, a tutela provisória (art. 294 e seguintes) se divide em tutela fundada 
na urgência (antecipada ou cautelar e que pode ser requerida em caráter antecedente ou incidente) e em tutela de evidência.

$\mathrm{O}$ art. 20 do marco civil da internet prescreve que sempre que tiverem informações de contato do usuário diretamente responsável pelo conteúdo a que se refere o art. 19, "caberá ao provedor de aplicações de internet comunicar-lhe os motivos e informações relativos à indisponibilização de conteúdo, com informações que permitam o contraditório e a ampla defesa em juízo", salvo expressa previsão legal ou expressa determinação judicial fundamentada em contrário. E o parágrafo único dispõe que, quando solicitado pelo usuário que disponibilizou o conteúdo tornado indisponível, "o provedor de aplicações de internet que exerce essa atividade de forma organizada, profissionalmente e com fins econômicos substituirá o conteúdo tornado indisponível pela motivação ou pela ordem judicial que deu fundamento à indisponibilização".

Outrossim, no art. 21, o marco civil da internet excepciona os casos de conteúdos de nudez ou atos sexuais de caráter privado, prevendo a responsabilidade subsidiária do provedor de aplicações que se omita diante de simples notificação. Além disso, não raro provedores de aplicações contam com sistemas próprios, previstos em termos e condições de uso, políticas de privacidade etc., para denunciação, notificação e remoção de conteúdo, que podem dar uma resposta prática eficiente a conflitos, talvez evitando a ida ao Judiciário ${ }^{29}$. Por esses motivos, para Garcia, diante de exceções bastante limitadas, abre-se um espaço mais que legítimo para questionamentos. Para o autor, não surpreende que a questão da responsabilidade civil de provedores de aplicações por conteúdo de terceiros pareça estar ainda longe de ser resolvida. E "será preciso decorrer mais tempo para análise crítica, para que a nova regra seja amadurecida, e para se avaliar como ela será entendida e aplicada pelos tribunais - e como o STJ irá uniformizar a sua interpretação"30.

\subsection{RESPONSABILIDADE DOS MECANISMOS DE BUSCA}

Especificamente sobre a extensão dessa responsabilidade aos mecanismos de busca, Silvestre e Benevides destacam a decisão de 13.04.2014 do Tribunal Justiça da União Europeia, que determinou a responsabilidade do Google e de outros motores de busca pela exclusão de certos dados e informações dos resultados da busca

\footnotetext{
${ }^{29}$ GARCIA, op. cit., p. 8.

${ }^{30}$ GARCIA, op. cit., p. 8.
} 
efetuadas por esses sites. Sendo que este entendimento se coaduna perfeitamente com a proteção ao direito da personalidade, "uma vez que a pessoa que tem seus dados, muitas vezes vexatórios, expostos na rede e gravados para a eternidade se mostram hipossuficientes em relação à exclusão deste conteúdo que se replica e se espalha em velocidade vertiginosa". ${ }^{31}$ No entanto, no Brasil, não se trata a questão da mesma forma.

Entretanto, em que pese tal posição da União Europeia, o Brasil, que já debateu o direito ao esquecimento na VI Jornada de Direito Civil, culminando inclusive no Enunciado 531, se nega a atribuir qualquer papel aos motores de busca que disponibilizam seus serviços na internet. A jurisprudência do STJ se mostra pacífica ao reconhecer o Google apenas como um facilitador de busca de dados, inexistindo para ele o dever de excluir ou limitar qualquer conteúdo no resultado de suas buscas. Para os tribunais brasileiros, caso um site divulgue conteúdo pessoal, não autorizado ou que cause comprovadamente constrangimento ao indivíduo, este deverá contatar o responsável pela página para remoção do conteúdo, ou seja, caso o conteúdo tenha sido replicado centenas de vezes e publicado em centenas de páginas, caberá à vítima buscar cada um dos responsáveis para então poder exigir a retirada de tal conteúdo ${ }^{32}$.

Dessa forma, diante deste posicionamento, o indivíduo lesado poderá encontrar uma série de dificuldades, entre elas:

(a) impossibilidade de identificação do responsável pela página, eis que é possível criar ou emular falsos IPs; (b) identificação do responsável, mas impossibilidade de sua localização; (c) impossibilidade de submissão do responsável pela página à jurisdição nacional, uma vez que internet é global e o agressor muitas vezes só poderá ser acionado mediante cooperação internacional; (d) a ofensa é tão grave e danosa que exige medidas de urgência; (e) a agressão está veiculada em grande quantidade de páginas, tornando inviável a propositura

31 BENEVIDES, Nauani Schades; SILVESTRE, Gilberto Fachetti. O papel do Google na eficácia do direito ao esquecimento - análise comparativa entre Brasil e Europa. Revista de Direito Privado, v. 70, p. 99-122, Out, 2016. Johan Hélder Oliveira Bahia também trata da decisão no âmbito da União Europeia nos seguintes termos: "Ademais, insta destacar que o Tribunal de Justiça da União Europeia, em 13.04.2014, exarou decisão em que a Google é obrigada a excluir links de buscas a partir da solicitação dos usuários, afirmando que qualquer pessoa tem o "direito de ser esquecida" na rede mundial de computadores, já que fatos tidos como ofensivos aos direitos da personalidade, inerente a pessoa, que foram publicados outrora e que, ainda assim, permanecem no histórico da Google (site de pesquisa), humilhando a reputação da vítima, logo, qualquer pessoa pode obter esse direito de solicitar a eliminação dessas informações, já que elas não têm nenhuma utilidade pública, e por causa da gravidade e ofensa ao direito à vida privada de cada indivíduo.39 Destaca-se, tal ponto, uma vez que o Poder Judiciário precisa, urgentemente, verificar essa questão, diga-se de passagem, muito bem fundamentada pela Corte Suprema da União Europeia, em razão de a vítima ter o direito de ser esquecida da Internet, eis que a informação a ela imputada, não é pertinente, não tem utilidade pública. Vale destacar que essa decisão só vincula aos países daquele continente." BAHIA, John Hélder Oliveira. Responsabilidade civil dos sites de buscas e provedores de Internet. Revista dos Tribunais Nordeste, v. 5, p. 279 - 299, Mai./Jun., 2014.

32 BENEVIDES, op. cit., p. 15. 
de ações judiciais em face de todos, seja por demandas autônomas ou por litisconsórcio passivo; (f) ainda que localizado e demandado o agressor, este em que pese todos os meios Estes são alguns dos desafios que aquele que deseja ver apagado da rede algum conteúdo pessoal indevido deverá enfrentar, o que demonstra o quanto a posição adotada pelos tribunais pátrios prejudica a vítima deste tipo de exposição na internet. Para poder ver efetivado o seu direito ao esquecimento, o indivíduo deverá enfrentar verdadeiro trabalho hercúleo, que lhe tomará muito tempo, lhe desgastará psicologicamente e muitas vezes o resultado pretendido não será alcançado.33

Por isso, os autores propõem a atribuição de maior papel a estes mecanismos na efetivação do direito ao esquecimento, assim como tem sido feito na Comunidade Europeia. "Não se pode ignorar que os motores de busca devem cuidar do conteúdo que expõem ante a potencialidade de dano neste ambiente, uma vez que proporciona a inúmeros usuários a localização de conteúdo, seja ele lícito ou ilícito, levando a multiplicação de visitas a estas páginas, o que lhe gera lucro". Até porque, se estas empresas auferem lucro com suas atividades, devem também ter alguma responsabilidade na mitigação dos danos causados por meio delas, seria um papel baseado no risco proveito. Nesse sentido, considera-se de suma importância a aprovação da Lei de Proteção de Dados Pessoais no Brasil, atualmente projeto de lei $\mathrm{n}^{\mathrm{o}}$. 5.276 (BRASIL, 2016), para poder regulamentar efetivamente o controle de uso, tratamento e armazenamento de dados, o que seria um grande avanço na luta pela efetivação deste direito no âmbito digital ${ }^{34}$.

Há algumas decisões isoladas que têm entendido que há sim responsabilidade dos mecanismos de busca, como, por exemplo, um juiz da 14ª Vara Cível, do Estado do Maranhão, condenou a Google a pagar indenização por notícia publicada em blog anônimo, com multa diária de $\mathrm{R} \$ 2.000,00$, limitada a quantia de $\mathrm{R} \$ 70.000,00$, conforme notícia disponível no Portal do Poder Judiciário do Maranhão na internet. Do mesmo modo, o Tribunal de Justiça do Rio Grande do Sul já reconheceu a legitimidade dos mecanismos de busca para a espécie de demanda em questão ${ }^{35}$.

33 BENEVIDES, op. cit., p. 15.

${ }^{34}$ BENEVIDES, op. cit.

35 No caso concreto, é cediço que a empresa ré é detentora de poderosa ferramenta de busca e pesquisa de conteúdo disperso pela internet acessível pelo site Google.com, por intermédio do qual, segundo o documento das fls. 12/13, é possível visualizar informações ligadas ao nome da parte autora em diferentes páginas da web, em especial, aquela disponibilizada pelo site desta Corte (www3.tjrs.jus.br/serviços/diário_justiça/pag_move. php?tp...) noticiando processo criminal.

${ }^{[\cdots . . .]}$ Ainda que quem disponibilize a informação não seja a empresa ré, mas terceiro alheio à lide, sua legitimidade está caracterizada quanto à facilidade de acesso das informações dispersas pela internet, mediante o serviço prestado pelo seu site de buscas, a partir de critérios selecionados pelo usuário. Daí, surge a relação de direito material deduzida em juízo, incrementando integralmente as condições da ação.

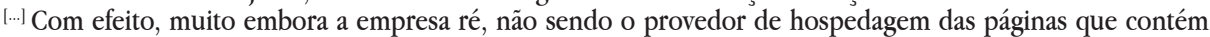
a informação tida pela parte apelante como autora de danos de sua imagem, remanesce sua legitimidade ad causam em abstrato. Trata-se de consequência de manter o site de buscas que universaliza os mais diversos conteúdos presentes na rede mundial de computadores, dentre os quais, aquele apontado como causador de prejuízos à imagem da parte apelante. (Apelação Cível No 70039338850,2010$)$ 
Contudo, no Tribunal de Justiça do Estado do Paraná, ao se buscar os termos "mecanismo de busca", encontram-se apenas julgados que não responsabilizam os provedores de busca, a exemplo do Agravo de Instrumento $\mathrm{N}^{\mathrm{O}} 1216454-0$, que diferentemente do Tribunal de Justiça do Rio Grande do Sul, reconheceu a ilegitimidade passiva do Google para responder a demanda. E, ainda, de modo a não responsabilizar os mecanismos de busca, o Agravo de Instrumento $\mathrm{n}^{\mathrm{o}} 31318432-4$ e a Apelação $n^{\circ}$ 11536323-2. No mesmo sentido, é o entendimento do Superior Tribunal de Justiça e da ministra Nancy Andrighui, segundo a qual, tem-se que os provedores de pesquisa: (i) não respondem pelo conteúdo do resultado das buscas realizadas por seus usuários; (ii) não podem ser obrigados a exercer um controle prévio do conteúdo dos resultados das buscas feitas por cada usuário; e (iii) não podem ser obrigados a eliminar do seu sistema os resultados derivados da busca de determinado termo ou expressão, tampouco os resultados que apontem para uma foto ou texto específico, independentemente da indicação do URL da página em que este estiver inserido.

Ademais, em relação à decisão do STJ proferida no julgamento do Recurso Especial $\mathrm{n}^{\mathrm{0}} 1.316 .921 / \mathrm{RJ}$, observa-se que houve o reconhecimento da existência de relação de consumo na prestação do serviço pelo provedor de pesquisa de internet, mas se negou o pleiteado direito à filtragem prévia das buscas e à retirada de resultados desabonadores, os quais associassem o nome da autora à pedofilia ou à qualquer outra prática criminosa. "No julgamento sob comentário, a Corte decidiu pela liberdade de informação, deixando de considerar, no entanto, que no caso concreto a informação é inverídica e extremamente desabonadora". Além disso, deixou de reconhecer que o fiel da balança deve ser o valor da dignidade da pessoa humana e que, na sociedade de consumo pós-moderna em que se vive, a atribuição dos ônus deve dar-se conforme um paradigma de solidariedade. Em sentido oposto ao que resultou na improcedência total do pedido da autora, ressalta-se que "a incidência do CDC, dos princípios constitucionais e da ideia de justiça distributiva deveriam ter guiado a decisão do caso em sentido diverso, não se mostrando constitucional a perpetuação dos danos a que vem sendo submetida a autora da presente ação"36.

Bahia $^{37}$ concorda com a responsabilização, realizando apenas algumas ressalvas:

${ }^{36}$ BARBOSA, Fernanda Nunes. Internet e consumo: o paradigma da solidariedade e seus reflexos na responsabilidade civil do provedor de pesquisa. Revista dos Tribunais, v. 924, p. 535-561, Out. 2012.

${ }^{37}$ BAHIA, op. cit., p. 11. 
Não obstante isso, quando o provedor de serviço retira o conteúdo tido como ofensivo e, ainda assim, os sites de buscas deixam em seu histórico a informação infringente, contendo nome e sobrenome da vítima ou dados pessoais, acredita-se que o provedor de pesquisa deve eliminar tal informação, já que não existe mais no provedor de serviços esse conteúdo ilícito, bem como a pessoa ofendida não pode suportar, por toda uma vida, a permanência de uma informação que humilha sua honra, rotula a sua imagem, tendo essa informação de ser apagada da rede mundial de computadores. Portanto, neste ponto, deve sim, o provedor de pesquisa, em colaboração com o site de conteúdo, procurar o meio de eliminar do histórico tal informação, pois, se a informação é imoral, inidônea, esta não deve existir, até porque, a Constituição veda a violação aos direitos da personalidade, sendo passível de indenização.

[...]

Ademais, o dano moral é um mecanismo que pode frear essa falta de controle por parte dos provedores, isto é, estes que percebem lucros de suas atividades, devem, também, se responsabilizar pelos danos ocasionados por estas. Até porque, se o ambiente virtual é visto pelos internautas, seja para o bem ou para o mal, a empresa lucra pelo número de visualizações, pois gerará interesse dos investidores para disponibilização de publicação das marcas destes nos sites com maior número de visualizações e acesso de pessoas. “(...) Fala-se, assim, em responsabilidade decorrente do risco proveito, do risco criado, do risco profissional e do risco da empresa e de recorrer à mão de obra alheia etc. Quem cria os riscos deve responder pelos eventuais danos aos usuários ou consumidores" ${ }^{\star 2}$.

Assim, o autor entende que é incompreensível que "o provedor que tem ferramenta de pesquisar, armazenar conteúdos, não pode criar mecanismos de controle que possam prevenir danos". Defendendo que se os sites de busca e os provedores de aplicação de internet disponibilizam sua propriedade, espaço digital, para qualquer usuário postar o que bem entender, ou seja, sem prévio controle, sem oferecer mecanismos de freios, devem ser responsabilizados de forma solidária com o agente/ofensor ${ }^{38}$.

Ademais, em nosso ordenamento jurídico há elementos suficientes para se responsabilizar os mecanismos de busca pela disponibilização de conteúdo inadequado ou descumprimento de ordem judicial nesse sentido. Isso porque, como bem preceitua Laura Schertel Mendes, a análise do regime jurídico do tratamento de dados pessoais dos usuários da internet exige, além da interpretação da lei $n^{\circ}$ 12.965/2014, a interpretação do Código de Defesa do Consumidor (CDC) (BRASIL,

\footnotetext{
${ }^{38}$ BAHIA, op. cit.
} 
1990), também aplicável ao espaço digital. O âmbito de aplicação do CDC, inclusive, é definido em seu art. $3^{\circ}, \S 2^{\circ}$, segundo o qual o Código é aplicável aos serviços fornecidos no mercado de consumo mediante remuneração. Tal conceito abrange as transações realizadas pela internet, incluindo aquelas que não acarretam diretamente ônus aos usuários. "Conforme interpretação dominante da jurisprudência, um serviço pode ser oferecido gratuitamente ao consumidor e, ainda assim, ser considerado remunerado, tendo em vista que obtém ganhos indiretos". É o que ocorre com diversos serviços e aplicações na internet, que, embora aparentemente gratuitos, se remuneram por meio de publicidade e da comercialização dos dados de navegação do usuário ${ }^{39}$. Nas palavras de Mendes ${ }^{40}$,

O Código de Defesa do Consumidor foi um dos precursores na previsão de normas sobre proteção de dados pessoais no ordenamento jurídico brasileiro, como se percebe a partir de seu art. 43. Este inovou na forma de regulamentação dos cadastros e bancos de dados de consumo no Brasil, permitindo o funcionamento desses bancos de dados dentro de parâmetros legais claros. Para além dessa norma, o Código estabelece princípios que devem nortear as ações de todos os atores das relações de consumo, tais como o reconhecimento da vulnerabilidade do consumidor (art. 4. ${ }^{\circ}$, I), a garantia de serviços e produtos com padrões com qualidade, segurança, durabilidade e desempenho (art. $4^{\circ}$, II,$d$ ), o respeito à boa-fé objetiva (art. $4 .^{\circ}$, III) e o incentivo à criação pelos fornecedores de meios eficientes de solução de conflitos (art. 4. $\left.{ }^{\circ}, \mathrm{V}\right)$. Podem-se citar também os direitos básicos previstos no Código, como a proteção da vida, saúde e segurança (art. 6. $\left.{ }^{\circ}, \mathrm{I}\right)$, a informação adequada e clara sobre os diferentes produtos e serviços (art. $\left.6 .^{\circ}, \mathrm{III}\right)$, a proteção contra práticas abusivas (art. 6. $\left.{ }^{\circ}, \mathrm{IV}\right)$, a efetiva prevenção e reparação de danos morais (art. $\left.6 .^{\circ}, \mathrm{VI}\right)$, bem como o acesso aos órgãos judiciários e administrativos (art. 6. $\left.{ }^{\circ}, \mathrm{VII}\right)$.

Nota-se, assim, que o Código de Defesa do Consumidor estabelece uma proteção integral da pessoa nas relações de consumo, seja dos seus interesses econômicos, seja da sua integridade e personalidade. Ademais, o caráter principiológico das suas normas tem se mostrado aberto o suficiente para oferecer soluções para os novos conflitos relacionados à tecnologia da informação. O papel central que o Código de Defesa do Consumidor exerce para a proteção da pessoa no ordenamento jurídico brasileiro, para além do mero funcionamento adequado do mercado, pode ser explicado em razão da sua origem e de sua vinculação constitucional (art. $5^{\circ}$, XXXII e 170 , V, da Constituição Federal e art. 48 de suas Disposições Transitórias). De especial importância se reveste, no contexto da sociedade da informação, o

${ }^{39}$ MENDES, Laura Schertel. O diálogo entre o Marco Civil da Internet e o Código de Defesa do Consumidor. Revista de Direito do Consumidor, v. 106, p. 37-69, Jul./Ago, 2016.

${ }^{40}$ MENDES, Ibidem, p. 4. 
art. $5^{\circ}$, XXXII, que determina que "o Estado promoverá, na forma da lei, a defesa do consumidor". Essa norma expressa um dever de proteção (Schutzpflicht), ${ }^{13}$ que é direcionada ao Estado como um todo - aos poderes Executivo, Legislativo e Judiciário. ${ }^{14} \mathrm{O}$ dever de proteção pode envolver, nesse contexto, várias dimensões: dever de interpretação conforme a Constituição, de modo a se levar em conta a vulnerabilidade do consumidor e a sua necessidade de proteção; dever de atuação administrativa para a proteção do consumidor; dever de desenvolvimento de uma arquitetura regulatória para a efetividade dessa proteção.

[...] Conforme explicado por Claudia Lima Marques, o diálogo das fontes é "a atual aplicação simultânea, coerente e coordenada das plúrimas fontes legislativas, leis especiais (como o Código de Defesa do Consumidor, a lei de seguro-saúde) e gerais (como o CC/2002 (LGL $\backslash 2002 \backslash 400)$ ), com campos de aplicação convergentes, mas não mais iguais." 15

Destaca-se também a aplicação da lei brasileira aos provedores de aplicação sediados em país estrangeiro. Anteriormente ao marco civil da internet, em relação ao provedor de aplicação sem filial no Brasil, se um usuário domiciliado no Brasil acessasse, via internet, tal provedor, estaria celebrando um contrato regido pela legislação estrangeira, nos termos do art. $9^{\circ}, \S 2^{\circ}$, da Lei de Introdução às Normas do Direito Brasileiro. E no tocante ao provedor de aplicações com filial no Brasil, estaria celebrando um contrato regido pela legislação brasileira, até mesmo pelo entendimento do Superior Tribunal de Justiça, no sentido de que as multinacionais com filial no Brasil que promovam marketing direcionado aos consumidores brasileiros, sujeitam-se às regras nacionais, ainda que contratem com brasileiros em terra estrangeira, a exemplo do Recurso Especial n ${ }^{0} 63.981^{41}$.

Com o marco civil da internet, à luz de seu art. $11^{\circ}$, a legislação brasileira terá de ser obrigatoriamente respeitada por qualquer empresa estrangeira, que mesmo não tendo filial no Brasil, oferte serviço ao público estrangeiro, nos termos de seu $\S 2^{042}$.

${ }^{41}$ OLIVEIRA, op. cit., p. 9-11.

${ }^{42}$ Art. 11. Em qualquer operação de coleta, armazenamento, guarda e tratamento de registros, de dados pessoais ou de comunicações por provedores de conexão e de aplicações de internet em que pelo menos um desses atos ocorra em território nacional, deverão ser obrigatoriamente respeitados a legislação brasileira e os direitos à privacidade, à proteção dos dados pessoais e ao sigilo das comunicações privadas e dos registros.

$\S 1$ o $\mathrm{O}$ disposto no caput aplica-se aos dados coletados em território nacional e ao conteúdo das comunicações, desde que pelo menos um dos terminais esteja localizado no Brasil.

$\S 2 \mathrm{O} O$ disposto no caput aplica-se mesmo que as atividades sejam realizadas por pessoa jurídica sediada no exterior, desde que oferte serviço ao público brasileiro ou pelo menos uma integrante do mesmo grupo econômico possua estabelecimento no Brasil.

§ $3^{\circ}$ Os provedores de conexão e de aplicações de internet deverão prestar, na forma da regulamentação, informações que permitam a verificaçã̃o quanto ao cumprimento da legislação brasileira referente à coleta, à guarda, ao armazenamento ou ao tratamento de dados, bem como quanto ao respeito à privacidade e ao sigilo de comunicações. 
E, para Oliveira ${ }^{43}$, não é qualquer norma que atingirá os provedores estrangeiros sem filial no Brasil, "mas apenas as normas que tratam da coleta, guarda, armazenamento ou tratamento de registros, dados pessoais ou de comunicações, o que se extrai da própria redação do artigo em comento". Dessa forma, se não houver oferta direcionada ao público brasileiro, mas apenas tradução do site português, não seria aplicável a legislação brasileira, nem mesmo em relação às normas estas normas que tratam da coleta e armazenamento de registros e dados.

Sendo que este entendimento prevalece ainda que o Termo de Uso de tais mecanismos de busca disponha de forma diferente. E, consoante acima se verificou, há que se aplicar a legislação brasileira, e, ainda, há que se considerar que o IP da máquina que acessa esses provedores de aplicações está no Brasil, constituindo-se na identificação de entrada do dado no sistema. ${ }^{44}$

\section{CONSIDERAÇÕES FINAIS}

Consoante se verificou ao longo do presente trabalho, o marco civil da internet traz conceitos elementares, a exemplo da definição de terminal e de endereço IP, assim como estabelece princípios e dá as diretrizes da regulamentação da internet. Também diferencia os problemas relacionados à guarda, ao sigilo e à responsabilidade sobre os dados dos usuários e o papel dos provedores, sendo que uma das maiores dificuldades constitui-se na tensão entre o direito à privacidade e o direito à informação.

Nesse contexto, foram analisados os mecanismos de busca, que podem ser considerados programas de computador que executam diversas tarefas com o objetivo de possibilitar a localização de arquivos e web sites que contenham ou guardem relação com a informação solicitada pelo usuário. Ou seja, os denominados mecanismos de busca são sites especializados em localizar informações na internet. Dessa

$\overline{43}$ OLIVEIRA, op. cit., p. 12.

${ }^{44}$ Sobre o assunto, João Costa Ribeiro Neto assevera que o Google, por exemplo, não possui a intenção de simplesmente não atuar no Brasil ou em outros países, em razão de eventuais restrições legislativas, tendo em vista que continua na China, com uma legislação extremamente rigorosa, por exemplo. De qualquer forma, aduz que não se deve menosprezar o enorme poder de barganha que detém um site de mecanismo de busca como o Google, por exemplo; primeiro, porque se estima que o grupo, como um todo, valia mais de 72 bilhões de dólares em 2011, valor superior ao PIB de 130 dos, aproximadamente, 190 países do globo; e, segundo, porque é um ator transterritorial, "de modo que é cada vez mais difícil, embora não impraticável, impor a vedação de um conteúdo ou de uma prática dentro de um limite territorial, quando o "espaço virtual" não se organiza territorialmente". RIBEIRO NETO, op. cit. 
forma, digita-se o termo procurado, numa caixa em branco disponibilizada no site e, em seguida, solicita-se que a busca seja efetuada, sendo que os pesquisadores procuram a ocorrência deste termo em seus bancos de dados e apresentam os resultados na forma de uma lista de documentos da internet que contém as palavras pesquisadas.

Na sequência, na tentativa de verificar a possível responsabilidade dos mecanismos de busca pelo conteúdo disponibilizado por terceiros na internet, passouse a se analisar tal responsabilidade de provedores de aplicação no marco civil da internet, que é regulamentada no seu art. 19. Este, com o intuito de assegurar a liberdade de expressão e impedir a censura, dispõe que "o provedor de aplicações de internet somente poderá ser responsabilizado civilmente por danos decorrentes de conteúdo gerado por terceiros se, após ordem judicial específica, não tomar as providências para, no âmbito e nos limites técnicos do seu serviço e dentro do prazo assinalado, tornar indisponível o conteúdo apontado como infringente", ressalvadas as disposições em sentido contrário constantes na legislação. Já o $\S 1^{\circ}$ prescreve que a ordem judicial de que trata o dispositivo deverá conter, sob pena de nulidade, identificação clara e específica do conteúdo apontado como infringente, permitindo "a localização inequívoca do material". No entanto, apesar da regulamentação da questão, verifica-se que a jurisprudência deverá definir em quais situações esta responsabilidade será subsidiária especialmente pela falha do serviço quanto à não identificação do terceiro ofensor.

Ademais, no ordenamento jurídico brasileiro há elementos suficientes para se responsabilizar os mecanismos de busca pela disponibilização de conteúdo inadequado ou descumprimento de ordem judicial nesse sentido. Isso porque, a análise do regime jurídico do tratamento de dados pessoais dos usuários da internet exige, além da interpretação da lei $\mathrm{n}^{0}$ 12.965/2014, a interpretação do Código de Defesa do Consumidor, também aplicável ao espaço digital. O âmbito de aplicação do CDC, inclusive, é definido em seu art. $3^{\circ}, \S 2^{\circ}$, segundo o qual o Código é aplicável aos serviços fornecidos no mercado de consumo mediante remuneração. Tal conceito abrange as transações realizadas pela internet, incluindo aquelas que não acarretam diretamente ônus aos usuários. "Conforme interpretação dominante da jurisprudência, um serviço pode ser oferecido gratuitamente ao consumidor e, ainda assim, ser considerado remunerado, tendo em vista que obtém ganhos indiretos". É o que ocorre com diversos serviços e aplicações na internet, que, embora aparentemente 
gratuitos, se remuneram por meio de publicidade e da comercialização dos dados de navegação do usuário.

Também se destaca a aplicação da lei brasileira aos provedores de aplicação sediados em país estrangeiro. Com o marco civil da internet, à luz de seu art. $11^{\circ}$, a legislação brasileira terá de ser obrigatoriamente respeitada por qualquer empresa estrangeira, que mesmo não tendo filial no Brasil, oferte serviço ao público estrangeiro, nos termos de seu $\S 2^{\circ}$. Sendo que este entendimento prevalece ainda que o Termo de Uso de tais mecanismos de busca disponha de forma diferente. E, consoante acima se verificou, há que se aplicar a legislação brasileira, e, ainda, há que se considerar que o IP da máquina que acessa esses provedores de aplicações está no Brasil, constituindo-se na identificação de entrada do dado no sistema.

\section{REFERÊNCIAS}

AQUINO JÚNIOR, Geraldo Frazão de. A responsabilidade civil no âmbito do Marco Civil da Internet. Revista dos Tribunais Nordeste, v. 5, p. 257-277, mai./jun., 2014.

ARAÚJO, Fabio Caldas. Reflexões sobre o Marco Civil da Internet. Consultor Jurídico. Disponível em: <http://www.conjur.com.br/2014-jul-04/fabio-caldas-araujo-reflexoes-marco-civil-internet>. Acesso em: 05 nov. 2016.

ARAÚJO, Laís Targino Casullo de; REIS, Sérgio Cabral dos. Responsabilidade civil dos provedores de conteúdo de internet. Âmbito Jurídico, Rio Grande, XIV, n. 93, out 2011. Disponível em: < http://www.ambito-juridico.com.br/site/?n_link=revista_artigos_leitura\&artigo_id=10422>. Acesso em: 05. nov. 2016.

BAHIA, John Hélder Oliveira. Responsabilidade civil dos sites de buscas e provedores de Internet. Revista dos Tribunais Nordeste, v. 5, p. 279 - 299, Mai./Jun., 2014.

BENEVIDES, Nauani Schades; SILVESTRE, Gilberto Fachetti. O papel do Google na eficácia do direito ao esquecimento: análise comparativa entre Brasil e Europa. Revista de Direito Privado, v. 70, p. 99-122, Out, 2016.

BARBOSA, Fernanda Nunes. Internet e consumo: o paradigma da solidariedade e seus reflexos na responsabilidade civil do provedor de pesquisa. Revista dos Tribunais, v. 924, p. 535-561, Out. 2012. 
BECK, Ulrich. Sociedade de risco. São Paulo: Ed. 34, 2010.

BRANSKI, Regina Meyer. Localização de informações na internet: características e formas de funcionamento dos mecanismos de busca. Transinformação, Campinas, v. 12, n. 1, p. 11-19, June 2000. Disponível em: <http://www.scielo.br/scielo.php?script $=$ sci_arttext\&pid $=$ S0103-37862000000100002\&lng $=$ en\&nrm $=$ iso $>$. Acesso em: 05 nov. 2016.

BRASIL. Lei No 13.105, de 16 de março de 2015. Código de Processo Civil. Brasília, DF: Poder Executivo, 2015.

BRASIL. Constituição da República Federativa do Brasil de 1988. Brasília, DF: Poder Executivo. 1988.

BRASIL. Lei No 12.965 de 23 de abril de 2014. Marco Civil da Internet. Brasília, DF: Poder Executivo. 2014.

BRASIL. Projeto de Lei No 5.276 de 2016. Brasília, DF: Câmara dos Deputados. 2016.

BUENO, Cassio Scarpinella. Manual de direito processual civil. São Paulo: Saraiva, 2016.

DUPAS. Gilberto. Tensões contemporâneas entre o público e o privado. Ed. Paz e Terra, 2005.

GABRIEL, Martha Carrer Cruz. Sem e Seo: dominando o marketing de busca. $2^{\mathrm{a}}$. ed. São Paulo: Novatec Editora, 2012.

GARCIA, Rebeca. Marco Civil da Internet no Brasil: repercussões e perspectivas. Revista dos Tribunais, vol. 964, fev. 2016.

JONAS, Hans. O princípio da responsabilidade. Ed. Contraponto, 2006. net. São Paulo: Juarez de Oliveira, 2005. 
MARINO, Aline Marques; PASSOS, Jonatas Fonseca. Dilemas do meio ambiente digital: o Marco Civil da Internet, a responsabilidade civil dos buscadores e os sites não indexados. In: Anais do II Congresso Internacional de Direito - CONIDIR, setembro de 2014, UBM, Barra Mansa.

MENDES, Laura Schertel. O diálogo entre o Marco Civil da Internet e o Código de Defesa do Consumidor. Revista de Direito do Consumidor, v. 106, p. 37-69, Jul./ Ago, 2016.

OLIVEIRA, Carlos Eduardo Elias. Aspectos principais da Lei n. 12.965 de 2014, o Marco Civil da Internet: subsídios à comunidade jurídica. Brasília: Núcleo de Estudos e Pesquisas/CONLEG/Senado, abr./2014 (Texto para discussão n. 148). Disponível em: <www.senado.leg.br/estudos. Acesso em 29.04.2014>. Acesso em: 05 nov. 2016.

PAZZINATTO, Carlos Henrique; FREITAS, Cinthia Obladen de Almendra. O Direito ao Esquecimento frente aos Mecanismos de Memória Eterna. Revista Opinião Jurídica (Fortaleza), v. 13, p. 82-107, 2015.

PORTAL DO PODER JUDICIÁRIO DO MARANHÃ. Disponível em: < www.tjma.jus.br/ cgj/visualiza/sessao/50/publicacao/404435> . Acesso em: 05 nov. 2016.

PINHEIRO, Patrícia Peck. Direito Digital. 4. ed. São Paulo: Saraiva, 2010.

RIBEIRO NETO, João Costa. A eficácia dos direitos fundamentais nas relações privadas: o caso Google. Revista de Direito Constitucional e Internacional, v. 83, p. 177-210, abr./jun, 2013.

SCHAAL, Flávia Mansur Murad; SANTOS, Natália Nogueira. Propriedade intelectual, Internet e o Marco Civil. São Paulo: EDIPRO, 2016.

SILVEIRA, Sérgio Amadeu da. Marco Civil e a proteção da privacidade. Com ciência, n. 158, Campinas, maio de 2014. Disponível em: < http://comciencia.scielo.br/ scielo.php?script $=$ sci_arttext\&pid $=\$ 1519-76542014000400008 \& \operatorname{lng}=$ pt\&nrm $=\mathrm{i}-$ so >. Acesso em: 05 nov. 2016. 
TJRS. Apelação Cível No 70039338850, Nona Câmara Cível, Tribunal de Justiça do RS, Relator: Leonel Pires Ohlweiler, Julgado em 10.11.2010.

Recebido em: 18/12/2016 Aceito em: 01/11/2017 